\title{
Multifaceted role of TNF- $\alpha$ during the pathogenesis of rheumatoid arthritis
}

\author{
Ramanjaneya V. R. Mula, Rangaiah Shashidharamurthy* \\ Department of Pharmaceutical Sciences, Philadelphia College of Osteopathic Medicine, School of Pharmacy, Suwanee, USA \\ Email: * $\underline{\text { rangaiahsh@pcom.edu }}$
}

Received 9 July 2013; revised 9 August 2013; accepted 10 September 2013

Copyright (C) 2013 Ramanjaneya V. R. Mula, Rangaiah Shashidharamurthy. This is an open access article distributed under the Creative Commons Attribution License, which permits unrestricted use, distribution, and reproduction in any medium, provided the original work is properly cited.

\begin{abstract}
Tumor necrosis factor alpha (TNF- $\alpha$ ) a cytokine has been shown to be the key player during the pathogenesis of several autoimmune inflammatory disorders (presumably sterile inflammation) including rheumatoid arthritis (RA). Several studies have shown that TNF- $\alpha$ is mainly involved in the proinflammatory responses. However recent studies have reported multifunctional role of TNF- $\alpha$ during the development of RA. Therefore, in this article we have highlighted the distinct functions of TNF- $\alpha$ during pathogenesis of RA.
\end{abstract}

Keywords: Cytokines; Tumor Necrosis Factor- $\alpha$; Rheumatoid Arthritis; Inflammation

\section{TNF- $\alpha$ AS CHEMO-ATTRACTANT AT SYNOVIAL JOINTS FOR CD4+ T CELLS}

The organization of infiltrated cells in the arthritic microenvironment resembles the secondary lymphoid organ including the presence of CD4+ T cells [1]. Typically, in secondary lymphoid organs the presence of chemokine gradient is necessary for the localization of $\mathrm{T}$ cells, especially to interact maximally with antigen presenting cells [2]. The cytokine TNF- $\alpha$ plays a crucial role during the pathogenesis of RA [3]. The focal immunological function of TNF- $\alpha$ is thought to be the induction of several proinflammatory cytokines and stimulate the effector immune cells through interaction with TNF- $\alpha$ receptors. In addition TNF- $\alpha$ is also known to act as chemoattractant for various cells including $\mathrm{T}$ cells $[4,5]$. However, the additional role of TNF- $\alpha$ in early phase of T cell migration to arthritic microenvironment, especially adhesion

\footnotetext{
"Corresponding author.
}

and transmigration through endothelium is not clear. Therefore, Rossol et al. [6] observed that the interactions of TNF- $\alpha$ and TNFRI are necessary for T-cell migration into synovium using in vitro and ex vivo experiments.

"The results of Rossol et al. [6] study show that the interaction of TNF- $\alpha$ with receptor type 1 (TNFR 1$)$ is indeed a migratory stimulus for $C D 4+T$ cells in $R A$ patients which is a TNF- $\alpha$ gradient dependent".

In this article, the authors used horizontally oscillating microtome for synovial sections and confocal as well as fluorescent microscopic methods to follow the T lymphocyte migration. They also collected the migrated $\mathrm{T}$ lymphocytes for phenotyping. The in vitro transwell experiment was performed to ascertain that TNF- $\alpha$ is indeed required for $\mathrm{T}$ cell migration. In support of this, they also carried out the ex vivo $\mathrm{T}$ cell migration assay using synovial tissue section from RA patients by coincubating with autologous peripheral CD4+ T cells. The migrated $\mathrm{CD} 4+\mathrm{T}$ cells in the tissue sections were visualized by Fluorescent microscopy. The results showed that only the CD4+ T cells form RA patients migrated into synovial tissue but not from the healthy controls. In continuation with this observation, they found that the expression of TNFR1 and ICAM-1 is necessary for activated $\mathrm{CD} 4+\mathrm{T}$ cells to migrate into synovium. Subsequent flow cytometry results of cells isolated from synovial tissue show that expression of TNFR1 is specific in transmigrated activated $\mathrm{CD} 4+\mathrm{T}$ cells but not in control healthy volunteer $\mathrm{CD} 4+\mathrm{T}$ cells. Taken together, these results suggest that the TNF- $\alpha$ is necessary for CD4+ T cell migration in arthritic joints. At the conclusive point the goal of the investigation on the role of TNF- $\alpha$ in synovium which was proven concretely as a potential chemoattractnat may possibly pave way to develop therapy of TNF- $\alpha$ inhibitors as well as new approaches that can be more focused towards targeting T-cells that express TNFR1 in excess. 


\section{DISTINCT EFFECT OF TNF- $\alpha$ ON MACROPHAGES AND FIBROBLAST-LIKE SYNOVIOCYTES DURING RA}

A step-by-step manifestation of synovial inflammation in RA quietly transforms into chronic inflammation through elevated levels of many inflammatory mediators [7] of which TNF- $\alpha$ plays a key role during synovial inflammation. Both macrophages and fibroblast-like synovial cells (FLS) are most prominent among multiple cell types for prolonged synovial inflammation [8,9] in RA. In addition, TNF- $\alpha$ secreted at the arthritic microenvironment is known to influence these two cells differently. Activation of macrophages through TNF- $\alpha$ is transient, while the FLS are responsible for prolonged synovial inflammation [10]. The distinct role of TNF- $\alpha$ in activating the macrophages and FLS is not clearly understood. However, it can be postulated that the main function of macrophages is to promote the inflammation and later dampen the inflammation by triggering the tissue repair mechanism as protective role to avoid the local and systemic toxicity caused by high levels of inflammatory mediators [11]. Therefore, they may transiently respond to the TNF- $\alpha$ to initiate the inflammation in the early phase. Whereas, since FLS normal function is to create a mechanical platform of synovium [12] and usually never exposes to foreign antigens, therefore they may lack the haemostatic mechanism to control their activation during RA. However, the molecular mechanism of FLS activation leading to prolonged synovial inflammation is not clearly understood. An attempt to investigate the possible mechanism was carried out by Lee et al. [13] have shown that TNF- $\alpha$ induced FLS activation leads to uncontrolled NF- $\kappa$ B signaling in FLS resulting in secretion of cytokines, chemokines and metalloproteinases for longer period of time leading to persistent synovial inflammation.

" $T N F-\alpha$ induces prolonged canonical $N F-\kappa B$ signaling resulting in uncontrolled production of inflammatory mediators contributing to the persistent synovial inflammation during RA through FLS but not macrophages. In other words FLS may be the contributing cell type for chronic inflammation during $R A$ ".

The authors studied the distinct functional role of TNF- $\alpha$ using macrophages and FLS. The signaling mechanisms of NF- $\kappa \mathrm{B}$ were elucidated by western blot analyses and the protein involvement in transcriptional regulation was analyzed by histone acetylation, chromatin accessibility, and NF- $\kappa \mathrm{B}, \mathrm{p} 65$ and RNA polymerase II (Pol II) occupancy at the interleukin-6 (IL-6) promoter using chromatin immunoprecipitation and restriction enzyme accessibility assays. Lee et al. have shown macrophage and FLS stimulation by TNF- $\alpha$ is transient and sustained respectively during the inflammatory RA condition. The feedback inhibition of inflammatory responses mediated by ABIN-3, IRAK-M, SOCS-3, ATF-3 and STAT-3 are expressed at high level in macrophages while at a low level in FLS. This may be a contributing factor for persistence of synovial inflammation in RA through FLS. Further, TNF- $\alpha$ facilitated histone modification and increased accessibility for RNA polymerase II at IL-6 promoter site resulting in secretion of proinflammatory cytokine IL-6 in FLS. Taken together this investigation has shown that sustained inflammatory response by FLS through TNF- $\alpha$ mediated inflammatory gene transcriptions and protein expressions prolong the synovial inflammation. This may pave a way to make FLS as an additional target in countering the unresolved synovitis.

\section{DIFFERENTIAL FUNCTION OF TNF- $\alpha$ DURING INFLAMMATION AND OSTEOCLASTOGENESIS IN RA}

TNF- $\alpha$, a proinflammatory cytokine initiates the inflammatory response leading to edematic joint and subsequent bone destruction during the development of rheumatoid arthritis [3]. The bone destruction is mainly mediated by osteoclast, a cell of myeloid origin (OC). OC differentiation, maturation and activation are primarily mediated by RANKL and its receptor RANK. Recent studies have shown that TNF- $\alpha$ can magnify the process of osteoclastogenesis in the presence of RANKL [14-16] as an additional role apart from its proinflammatory response. It has been shown that monoclonal antibody therapy (infliximab, etanercept and adalimumab) against TNF- $\alpha$, though inhibited/reduced the bone erosion after the treatment, the clinical symptoms of inflammation were not affected [17]. Nonetheless, the mechanism of the biphasic effect of biological TNF- $\alpha$ inhibitors was not yet fully understood. Therefore, Binder et al. [18] investigated the fundamental mechanism of TNF- $\alpha$ during RA by in vitro studies and human TNF- $\alpha$ (hTNF) transgenic destructive arthritis mouse model. Binder et al. have shown the differential effects of TNF- $\alpha$ on osteoclastogenesis and bone erosion activity using above mentioned mouse model of experimental arthritis.

"High level of TNF- $\alpha$ is required for osteoclastogenesis than to initiate the inflammation at the synovial joints. Hence, low doses of TNF- $\alpha$ inhibitor used in present investigation lead to expression of low levels of TNF- $\alpha$, which impede osteoclastogenesis but do not inhibit synovial inflammation. Therefore, high levels of TNF- $\alpha$ inhibitors are required to inhibit both inflammation and bone resorption".

The authors have chosen monocytes derived from spleen cells and tested the osteoclastogenesis in vitro us- 
ing different concentrations of TNF- $\alpha$ inhibitor adalimumab and activator RANKL. An hTNF-transgenic destructive arthritis mouse model was employed for in vivo studies of inhibition of osteoclast precursors by the therapeutic. The dose dependent differential effect of TNF- $\alpha$ on osteoclastogenesis though countered with low doses of immunotherapeutic inhibitor adalimumab even in the absence of RANKL, the inflammation of synovium was not affected. These data suggested that TNF- $\alpha$ alone can activate the osteoclasts. The mRNA levels of proinflammatory mediators such as IL-1, matrix metalloproteinase (MMP) 3, and MMP13 are significantly upregulated in untreated hTNF-transgenic mice compared to hTNFtransgenic mice treated with high concentration (10 $\mathrm{mg} / \mathrm{kg}$ body weight) of adalimumab. Whereas low dose $(0.1 \mathrm{mg} / \mathrm{kg})$ did not have any affect. Osteoclast associated genes such as NF-ATc1, cathepsin K, c-Fms, and $\mathrm{M}$-CSF were also upregulated at higher dose but, interestingly not at lower dose. These data suggest that antiresorptive activity of TNF- $\alpha$ was not affected at lower concentration but not synovial inflammation. Taken together Binder et al. [18] exemplified the need of controlling both cartilage destruction as well as inflammation mediated by TNF- $\alpha$ during the treatment of rheumatoid arthritis.

\section{ACKNOWLEDGEMENTS}

This work was supported by American Heart Association award (11SDG5710004) to R.S. The authors declare no competing financial interests.

\section{REFERENCES}

[1] Lundy, S.K., Sarkar, S., Tesmer, L.A. and Fox, D.A. (2007) Cells of the synovium in rheumatoid arthritis. T lymphocytes. Arthritis Research \& Therapy, 9, 202. http://dx.doi.org/10.1186/ar2107

[2] Crotty, S. (2011) Follicular helper CD4 T cells (TFH). Annual Review of Immunology, 29, 621-663. http://dx.doi.org/10.1146/annurev-immunol-031210-1014 $\underline{00}$

[3] Feldmann, M. and Maini, R.N. (2001) Anti-TNF alpha therapy of rheumatoid arthritis: What have we learned? Annual Review of Immunology, 19, 163-196.

http://dx.doi.org/10.1146/annurev.immunol.19.1.163

[4] de Jong, A.L., Green, D.M., Trial, J.A. and Birdsall, H.H. (1996) Focal effects of mononuclear leukocyte transendothelial migration: TNF-alpha production by migrating monocytes promotes subsequent migration of lymphocytes. Journal of Leukocyte Biology, 60, 129-136.

[5] Green, D.M., Trial, J. and Birdsall, H.H. (1998) TNFalpha released by comigrating monocytes promotes transendothelial migration of activated lymphocytes. The Journal of Immunology, 161, 2481-2489.

[6] Rossol, M., Schubert, K., Meusch, U., Schulz, A., Bied- ermann, B., Grosche, J., Pierer, M., Scholz, R., Baerwald, C., Thiel, A., Hagen, S. and Wagner, U. (2013) Tumor necrosis factor receptor type I expression of CD4+ T cells in rheumatoid arthritis enables them to follow tumor necrosis factor gradients into the rheumatoid synovium. $\mathrm{Ar}$ thritis \& Rheumatism, 65, 1468-1476. http://dx.doi.org/10.1002/art.37927

[7] Riegsecker, S., Wiczynski, D., Kaplan, M.J. and Ahmed, S. (2013) Potential benefits of green tea polyphenol EGCG in the prevention and treatment of vascular inflammation in rheumatoid arthritis. Life Sciences, 93, 307-312. http://dx.doi.org/10.1016/j.1fs.2013.07.006

[8] McInnes, I.B. and Schett, G. (2011) The pathogenesis of rheumatoid arthritis. The New England Journal of Medicine, 365, 2205-2219. http://dx.doi.org/10.1056/NEJMra1004965

[9] Fox, D.A. (1997) The role of T cells in the immunopathogenesis of rheumatoid arthritis: New perspectives. $A r-$ thritis \& Rheumatism, 40, 598-609. http://dx.doi.org/10.1002/art.1780400403

[10] Firestein, G.S. (2003) Evolving concepts of rheumatoid arthritis. Nature, 423, 356-361. http://dx.doi.org/10.1038/nature01661

[11] Ivashkiv, L.B. (2011) Inflammatory signaling in macrophages: transitions from acute to tolerant and alternative activation states. European Journal of Immunology, 41, 2477-2481. http://dx.doi.org/10.1002/eji.201141783

[12] Noss, E.H. and Brenner, M.B. (2008) The role and therapeutic implications of fibroblast-like synoviocytes in inflammation and cartilage erosion in rheumatoid arthritis. Immunological Reviews, 223, 252-270. http://dx.doi.org/10.1111/j.1600-065X.2008.00648.x

[13] Lee, A., Qiao, Y., Grigoriev, G., Chen, J., Park-Min, K.H., Park, S.H., Ivashkiv, L.B. and Kalliolias, G.D. (2013) Tumor necrosis factor alpha induces sustained signaling and a prolonged and unremitting inflammatory response in rheumatoid arthritis synovial fibroblasts. $\mathrm{Ar}$ thritis \& Rheumatism, 65, 928-938. http://dx.doi.org/10.1002/art.37853

[14] Lam, J., Takeshita, S., Barker, J.E., Kanagawa, O., Ross, F.P. and Teitelbaum, S.L. (2000) TNF-alpha induces osteoclastogenesis by direct stimulation of macrophages exposed to permissive levels of RANK ligand. Journal of Clinical Investigation, 106, 1481-1488. http://dx.doi.org/10.1172/JCI11176

[15] Abu-Amer, Y., Ross, F.P., Edwards, J. and Teitelbaum, S.L. (1997) Lipopolysaccharide-stimulated osteoclastogenesis is mediated by tumor necrosis factor via its P55 receptor. The Journal of Clinical Investigation, 100, 1557-1565. http://dx.doi.org/10.1172/JCI119679

[16] Kobayashi, K., Takahashi, N., Jimi, E., Udagawa, N., Takami, M., Kotake, S., Nakagawa, N., Kinosaki, M., Yamaguchi, K., Shima, N., Yasuda, H., Morinaga, T., Higashio, K., Martin, T.J. and Suda, T. (2000) Tumor necrosis factor alpha stimulates osteoclast differentiation by a mechanism independent of the ODF/RANKL-RANK interaction. The Journal of Experimental Medicine, 191, 275-286. http://dx.doi.org/10.1084/jem.191.2.275

[17] Smolen, J.S., Han, C., Bala, M., Maini, R.N., Kalden, 
J.R., van der Heijde, D., Breedveld, F.C., Furst, D.E., Lipsky, P.E. and Group, A.S. (2005) Evidence of radiographic benefit of treatment with infliximab plus methotrexate in rheumatoid arthritis patients who had no clinical improvement: A detailed subanalysis of data from the anti-tumor necrosis factor trial in rheumatoid arthritis with concomitant therapy study. Arthritis \& Rheumatism, 52, 1020-1030. http://dx.doi.org/10.1002/art.20982
[18] Binder, N.B., Puchner, A., Niederreiter, B., Hayer, S., Leiss, H., Bluml, S., Kreindl, R., Smolen, J.S. and Redlich, K. (2013) Tumor necrosis factor-inhibiting therapy preferentially targets bone destruction but not synovial inflammation in a tumor necrosis factor-driven model of rheumatoid arthritis. Arthritis \& Rheumatism, 65, 608617. http://dx.doi.org/10.1002/art.37797 